\title{
Suplementação de Novilhos Mestiços durante a Época das Águas: Parâmetros Ingestivos e Digestivos ${ }^{1}$
}

\author{
Edenio Detmann 2,3 , Mário Fonseca Paulino ${ }^{4,3}$, Joanis Tilemahos Zervoudakis ${ }^{2,3}$ \\ Sebastião de Campos Valadares Filho ${ }^{4,3}$, Rogério de Paula Lana ${ }^{4}$, Domingos Sávio de Queiroz ${ }^{5}$
}

RESUMO - Avaliaram-se os efeitos da suplementação durante o período das águas sobre os consumos de matéria seca total (CMS), forragem (CF), fibra em detergente neutro (CFDN) e proteína bruta (CPB); a digestibilidade da MS (DMS), FDN (DFDN) e PB (DPB); a taxa de passagem de partículas ruminal (TPR) e o tempo médio de retenção total (TMRT) da digesta; o pHe as concentrações de N-amoniacal do rúmen, em novilhos mestiços, sob regime de pastejo. Foram utilizados cinco novilhos F1 Limousin x Nelore, fistulados no rúmen e esôfago, manejados em pastagem de Brachiaria decumbens. O experimento foi conduzido em três períodos experimentais, seguindo um modelo de blocos casualizados, sendo os períodos considerados blocos. Foram fornecidos os seguintes suplementos: sal mineral (SAL), suplementos à base de milho e farelo de soja, com 20\% PB, nos níveis de 1,0 e 2,0 kg/dia (MS1 e MS2), suplementos à base de farelo de trigo e farelo de soja, com 20\% PB, nos níveis de 1,0 e 2,0 kg/dia (TS1 e TS2), fornecidos diariamente às $10 \mathrm{~h}$. A suplementação reduziu o CMS, CF e CFDN, em média, de 21,2, 33,6 e28,9\%, sendo aparentemente mais proeminentes para os tratamentos à base de milho, embora sem efeitos estatisticamente significativos. A TPR, TMRT e o pH ruminal não diferiram entre suplementos. Houve interação suplemento x tempo de coleta sobre a concentração de N-amoniacal, não havendo elevação dos níveis basais. Os tratamentos SAL e MS1 não diferiram entre si, não variando com o tempo. Os tratamentos MS2 e TS1 não diferiram entre si dentro de cada tempo, apresentando perfis quadráticos semelhantes ao de TS2, o qual demonstrou os maiores valores de concentração de $\mathrm{N}$-amoniacal nos tempos maiores que zero.

Palavras-chave: amônia ruminal, braquiária, consumo a pasto, digestibilidade, extrusa, suplementos múltiplos

\section{Supplementation of Crossbred Steers during the Rainy Season: Ingestive and Digestive Parameters}

\begin{abstract}
The effects of supplementation of crossbred steers on pasture during the wet season on dry matter (DMI), forage (FI), neutral detergent fiber (NDFI) and crude protein (CPI) intakes; digestibility of DM (DMD), NDF (NDFD) and CP (CPD); rate of passage of ruminal particles (RPR) and total mean retention time (TMRT) of the digesta; $\mathrm{pH}$ and concentrations of amoniacal-N in the rumen, were evaluated. Five F1 Limousin x Nelore steers fistulated in the rumen and esophagus and supplemented on Brachiaria decumbens pasture were used. The experiment was carried out in three experimental periods, according to a randomized blocks design, being the periods considered blocks. The supplements were: mineral salt (SAL); supplements based on corn and soybean meal, with $20 \% \mathrm{CP}$, at the level of 1.0 and $2.0 \mathrm{~kg}$ /day (MS1 and MS2); and supplements based on wheat bran and soybean meal, with $20 \% \mathrm{CP}$, at the level of 1.0 and $2.0 \mathrm{~kg} /$ day (TS1 and TS2), daily fed at $10 \mathrm{a} . \mathrm{m}$. The supplementation decreased DMI, FI, and NDFI, being more prominent for the supplements based on corn, although without significant effects. RPR, TMRT and ruminal $\mathrm{pH}$ did not differ among treatments. There was interaction supplement $x$ time of collection on concentration of amoniacal-N, without elevating the basal levels; the treatments SAL and MS1 did not differ and did not vary with the time. The treatments MS2 and TS1 did not differ at any time, presenting quadratic profiles, similar to TS2, which demonstrated the largest concentrations of amoniacal-N in the times other than zero.
\end{abstract}

Key Words: digestibility, extrusa, multiple supplements, pasture intake, ruminal ammonia, signal grass

\section{Introdução}

As pastagens tropicais, durante a estação das chuvas, apesar de não serem consideradas deficientes em proteína bruta, possibilitam ganhos de peso muito aquém dos observados, nas mesmas condições, em regiões temperadas (POPPI e McLENNAN,
1995), não permitindo taxas de ganho elevadas, próximas ao potencial genético do animal (KARGES et al., 1992; HESS et al., 1996; e ELIZALDE et al., 1998), constituindo um dos principais entraves no aumento do ganho de peso e na redução da idade ao abate (POPPI e McLENNAN, 1995). Assim, surge a necessidade de se avaliar o potencial das pastagens

\footnotetext{
${ }^{1}$ Parte da Dissertação de Mestrado do primeiro autor.

2 Zootecnista, MS, estudante de Doutorado, DZO-UFV. E.mail:detmann@alunos.ufv.br

3 Bolsista do CNPq

4 Professor DZO-UFV.

5 Pesquisador EPAMIG.
} 
tropicais em suprir nutrientes para altas taxas de ganho de peso durante a época das águas (PAULINO et al., 1996), e a suplementação em pasto surge como opção para o suprimento de nutrientes limitantes e aumento da eficiência de utilização das pastagens (POPPI e McLENNAN, 1995).

Devido à alta degradabilidade da proteína da pastagem durante o período das águas, muito desta se perde na forma de amônia, gerando déficit protéico em relação às exigências para ganhos elevados (POPPI e McLENNAN, 1995). Animais em pastejo, sob condições semelhantes, podem responder a aumento no suprimento de proteína, o que poderia ser obtido, diretamente, com o uso de suplementos de natureza protéica, ou, indiretamente, pelo emprego de suplementos energéticos, que auxiliariam no suprimento protéico para o animal, aumentando a fixação de amônia, em proteína microbiana, no ambiente ruminal (OBARA et al., 1991; KARGES et al., 1992; e POPPI e McLENNAN, 1995).

POPPI e McLENNAN (1995) afirmaram que a dissipação de calor aparece como a maior limitação à produção nos trópicos, em condições de pastagens. $\mathrm{O}$ estresse calórico implica em restrição de consumo e, portanto, de ganho, a uma taxa na qual o calor corporal possa ser dissipado confortavelmente, sendo normalmente agravado pela baixa relação proteína:energia nos substratos absorvidos, desviando o excesso acetogênico para a produção de calor e elevando a temperatura corporal, a qual inibe o consumo (LENG, 1990). A suplementação energético/protéica amplia a disponibilidade de proteína metabolizável (POPPI McLENNAN, 1995), aumentando a relação proteína:energia absorvida e a retenção de energia, reduzindo a produção de calor metabólico, favorecendo maiores consumos e, conseqüentemente, elevando as taxas de ganho (LENG, 1990; POPPI e McLENNAN, 1995).

Contudo, WALDO (1986) afirmou que a suplementação de forragem com concentrado geralmente amplia o consumo total de matéria seca (MS), decrescendo, porém, o consumo de forragem. Segundo o NATIONAL RESEARCH COUNCIL - NRC (1996), quando mais de $1 \mathrm{~kg}$ de suplemento é fornecido diariamente ao animal, a ingestão de forragem pode ser reduzida por substituição. A presença do efeito substitutivo parece ser mais marcante no emprego de suplementos de natureza energética (MINSON, 1990; POPPI e McLENNAN, 1995) e maior em condições de melhor qualidade da forragem (MINSON, 1990; CATON e DHUYVETTER, 1997).

As forragens tropicais, de forma geral, apresentam lenta taxa de passagem pelo trato gastrointestinal e baixa degradação da fibra, resultando, conseqüentemente, em baixo consumo voluntário (KENNEDY e MURPHY, 1988). Alguns autores têm encontrado efeitos benéficos da suplementação sobre a taxa de passagem (McCOLLUM e GALYEAN, 1985; HANNAH et al., 1991), embora efeitos nulos com o uso de suplementos, sobre este parâmetro, sejam freqüentemente relatados (JUDKINS et al., 1987; KRYSL et al., 1989).

Evidências experimentais apontam que o emprego de suplementos energéticos parece estar relacionado a reduções na digestibilidade da fração fibrosa da dieta, as quais parecem envolver reduções no pH ruminal (CHASE JR. e HIBBERD, 1987; HANNAH et al., 1991; HESS et al., 1996; e CATON e DHUYVETTER, 1997). Segundo CATON e DHUYVETTER (1997), as respostas do $\mathrm{pH}$, devido à suplementação, são inconsistentes, parecendo estar mais relacionadas à quantidade de suplemento fornecido.

A atividade da microbiota ruminal é dependente do nível de nitrogênio $(\mathrm{N})$ amoniacal presente no meio. $\mathrm{O}$ uso de suplementos pode auxiliar na implementação de níveis desejados, para melhor otimização do ambiente ruminal (HAFLEY et al., 1993). Contudo, em estações favoráveis ao crescimento da forragem, a alta degradabilidade protéica pode favorecer altos níveis de compostos nitrogenados amoniacais, que leva a perdas intensas por difusão (POPPI e McLENNAN, 1995). Nesses casos, o uso de suplementos de natureza energética provê energia adicional, para melhor sincronização na síntese de proteína microbiana, reduzindo as perdas e a concentração amoniacal ruminal (KARGES et al., 1992; POPPI e McLENNAN, 1995). Todavia, OBARA et al. (1991) sugeriram que suplementos energéticos podem ou não afetar o nível amoniacal do rúmen, o que poderia ser atribuído, em parte, à contribuição em $\mathrm{N}$ do suplemento em relação ao $\mathrm{N}$ basal da dieta e, portanto, ao total do consumo nitrogenado.

O objetivo deste trabalho foi avaliar os efeitos da suplementação durante o período das águas sobre os consumos de matéria seca total,de forragem, proteína bruta e fibra em detergente neutro; o pH, a concentração amoniacal e taxa de passagem ruminal; e a digestibilidade aparente total e das frações fibrosa e protéica da dieta.

\section{Material e Métodos}

O presente trabalho foi realizado na Fazenda Experimental de Felixlândia, em Felixlândia-MG, da 
1342 Rev. bras. zootec.

Empresa de Pesquisa Agropecuária de Minas Gerais (EPAMIG), entre dezembro de 1997 e março de 1998, durante a parte central do período chuvoso, conforme descrito na Tabela 1.

A área experimental, com 5,35 hectares e topografia plana, coberta uniformemente com a gramínea Brachiaria decumbens, foi dividida em cinco piquetes de 1,07 hectares, providos de bebedouro e comedouro coberto.

Foram utilizados cinco bovinos $\mathrm{F} 1$ Limousin $\mathrm{x}$ Nelore, fistulados no esôfago e rúmen, castrados, com idade e peso médios iniciais de 22 meses e $396 \mathrm{~kg}$.

$\mathrm{O}$ experimento constou de três períodos experimentais de 31 dias, sendo os sete primeiros de adaptação. Ao início de cada período experimental, os animais foram sorteados, aleatoriamente, com relação aos suplementos e piquetes.

Os suplementos fornecidos, listados abaixo, foram previamente balanceados para atingirem o nível de $20 \%$ PB, com base na matéria natural:

S.1 - controle, sem suplementação (SAL);

S.2 - suplemento constituído de milho e farelo de soja, fornecido no nível de $1 \mathrm{~kg} /$ cabeça/dia (MS1);

S.3 - suplemento constituído de milho e farelo de soja, fornecido no nível de $2 \mathrm{~kg} /$ cabeça/dia (MS2);

S.4 - suplemento constituído de farelo de trigo e farelo de soja, fornecido no nível de $1 \mathrm{~kg} /$ cabeça/dia (TS1); e

S.5 - suplemento constituído de farelo de trigo e farelo de soja, fornecido no nível de $2 \mathrm{~kg} /$ cabeça/dia (TS2).

No primeiro dia de cada período experimental, amostrou-se a forrageira por intermédio do corte de cinco áreas de $1 \times 1 \mathrm{~m}$, escolhidas aleatoriamente dentro de cada piquete, efetuando-se o corte ao nível do solo. Após a pesagem, procedeu-se à homogeneização das amostras por piquete, e dessas foram retiradas duas alíquotas compostas, uma para análise de disponibilidade total e outra para determinação do percentual das frações folha verde, colmo verde e matéria morta.

Para avaliação da dieta ingerida pelo animal, realizou-se, no terceiro dia de cada período experimental, às $7 \mathrm{~h}$, a coleta de extrusa, utilizando-se bolsas de fundo telado. De cada amostra de extrusa, retirou-se uma alíquota para produção de cromo mordante.

A excreção fecal foi estimada utilizando-se o óxido crômico como indicador externo, sendo o período de adaptação, para estabilização do perfil
Tabela 1 - Início, término e precipitação (PP) dos períodos experimentais

Table 1 - Beginning, end and rainfall (RF) of the experimental periods

\begin{tabular}{lccc}
\hline $\begin{array}{l}\text { Período } \\
\text { Period }\end{array}$ & $\begin{array}{c}\text { Início } \\
\text { Beginning }\end{array}$ & $\begin{array}{c}\text { Término } \\
\text { End }\end{array}$ & $\begin{array}{c}\mathrm{PP}(\mathrm{mm}) \\
R F(\mathrm{~mm})\end{array}$ \\
\hline 1 & $19 / 12 / 1997$ & $18 / 01 / 1998$ & 183,3 \\
2 & $19 / 01 / 1998$ & $18 / 02 / 1998$ & 212,6 \\
3 & $19 / 02 / 1998$ & $21 / 03 / 1998$ & 110,0 \\
\hline
\end{tabular}

nictemeral de excreção do indicador compreendido entre o primeiro e o sétimo dia do período experimental, realizando-se as coletas fecais entre o oitavo e décimo segundo dias, concomitantemente ao fornecimento do indicador (HOPPER et al., 1978). Empregou-se como indicador interno para estimação do consumo a fibra em detergente neutro indigestível (FDNi), obtida segundo metodologia descrita por LIPPKE et al. (1986).

A determinação da taxa de passagem foi realizada com cromo mordante, produzido a partir da extrusa, conforme técnica adaptada de UDÉN et al. (1980). A fibra mordantada foi acondicionada em cartuchos de papel, contendo $100 \mathrm{~g}$, e fornecida via fístula ruminal a cada animal no vigésimo sexto dia do período experimental, às $8 \mathrm{~h}$. As amostras de fezes foram coletadas nos tempos $0,6,9,12,15,18,21,24,27,30$, $33,36,42,48,54,60,72,84,96,108,120$ e 144 horas pós-dosagem, colocadas em sacos plásticos, identificadas e congeladas a $-20^{\circ} \mathrm{C}$.

A amostragem de material do rúmen, para determinação do pHe da amônia ruminal, foi realizada no vigésimo quarto dia do período experimental, imediatamente antes e 2, 4 e 6 horas após o fornecimento do suplemento.

Em todos os períodos de coleta, os animais foram levados ao tronco de contenção, no qual se retirou uma alíquota de líquido ruminal, preferencialmente da região de interface entre as fases sólida e líquida do ambiente ruminal, que foi filtrada por uma camada tripla de gaze e imediatamente submetida à análise em peagâmetro digital. Após a avaliação do $\mathrm{pH}$ do líquido ruminal, retirou-se uma alíquota de $40 \mathrm{~mL}$, a qual foi acondicionada em recipiente de vidro, contendo $1 \mathrm{~mL} \mathrm{HCl}$ (1:1), identificada e congelada a $-20^{\circ} \mathrm{C}$, para posterior análise de $\mathrm{N}$ amoniacal.

Todas as análises foram realizadas no Laboratório de Nutrição Animal do Departamento de Zootecnia da Universidade Federal de Viçosa.

As amostras de extrusa e fezes foram descongeladas à temperatura ambiente, secas em estufa ven- 
tilada a $65^{\circ} \mathrm{C}$ por 72 horas e, juntamente com as amostras de suplemento, processadas em moinho do tipo Willey, com peneira de $1 \mathrm{~mm}$, colocadas e identificadas em recipientes de vidro com tampa de polietileno. Posteriormente, procedeu-se às análises bromatológicas de cada amostra, a fim de determinar seu teor de MS, PB, extrato etéreo (EE), fibra em detergente neutro (FDN) e cinzas, conforme técnicas descritas por SILVA (1990).

Os carboidratos totais (CHOT) foram obtidos por intermédio da equação: 100 - (\%PB + \%EE + \% Cinzas) e os carboidratos-não estruturais (CNE), das diferenças entre CHOT e FDN (SNIFFEN et al., 1992). A composição bromatológica de extrusa e suplementos encontra-se na Tabela 2.

O líquido ruminal foi descongelado e centrifugado a 1000x g por 15 minutos, analisando-se o sobrenadante para teor de nitrogênio não-protéico total por uma adaptação do método de Kjeldahl, omitindo-se a fase de digestão. Pipetou-se uma alíquota de $2 \mathrm{~mL}$ do líquido sobrenadante em um tubo de ensaio, adicionando-se, em seguida $18 \mathrm{~mL}$ de água destilada, levandose posteriormente ao aparelho destilador. Adicionaram-se $15 \mathrm{~mL}$ de $\mathrm{KOH}(2 \mathrm{~N})$, destilando-se em $20 \mathrm{~mL}$ de ácido bórico, até o volume aproximado de $100 \mathrm{~mL}$. Procedeu-se à titulação com $\mathrm{HCl}(0,005 \mathrm{~N})$.
As amostras de fezes, fibra mordantada e óxido crômico foram analisadas quanto ao teor de cromo, em espectrofotômetro de absorção atômica, conforme metodologia descrita por WILLIANS et al. (1962).

Para estimação do consumo, foram empregadas as seguintes equações:

Excreção
fecal $(\mathrm{kg} / \mathrm{dia})=$

CMS $(\mathrm{kg} / \mathrm{dia})=\{[(\mathrm{EFxCIF})-\mathrm{IS}] / \mathrm{CIFO}\}+\mathrm{CMSS}$ em que CIF = concentração do indicador nas fezes $(\mathrm{kg} / \mathrm{kgMS}) ; \mathrm{CIFO}=$ concentração do indicador na forragem $(\mathrm{kg} / \mathrm{kgMS}) ; \mathrm{CMSS}=$ consumo de matéria seca de suplemento $(\mathrm{kg} / \mathrm{dia}) ; \mathrm{EF}=$ excreção fecal $(\mathrm{kg} /$ dia); e IS = indicador presente no suplemento ( $\mathrm{kg} / \mathrm{dia})$.

Para estimação dos parâmetros da cinética de trânsito ajustou-se às curvas de excreção fecal de cromoo modelobi-compartimental, tempo-independente, descrito por GROVUM e WILLIANS (1973), empregando-se para tal o procedimento Gauss-Newton, do programa SAEG, versão 7.1. O tempo médio de retenção total da digesta foi obtido por intermédio da soma das inversas das taxas de passagem do primeiro e segundo compartimento e do tempo de trânsito relacionado ao fluxo não-mixante do trato digestivo.

Tabela 2 - Teores médios $(\mathrm{g} / \mathrm{kg})$ de matéria seca $(\mathrm{MS})$, matéria orgânica (MO), proteína bruta (PB), extrato etéreo (EE), carboidratos totais (CHOT), fibra em detergente neutro (FDN), carboidratos não-estruturais (CNE) e cinzas, com base na matéria seca para a extrusa nos diferentes períodos experimentais e os suplementos à base de milho e farelo de soja (MS) e farelo de trigo e farelo de soja (TS)

Table 2 - Average contents ( $\mathrm{g} / \mathrm{kg}$ ) of dry matter (DM), organic matter (OM), crude protein (CP), ether extract (EE), total (TC) and non structural (NSC) carbohydrates, neutral detergent fiber (NDF) and ash, in dry matter basis, for extrusa, in different experimental periods, and corn and soybean meal (MS) and wheat bran and soybean meal (TS) based supplements

\begin{tabular}{|c|c|c|c|c|c|}
\hline & \multicolumn{3}{|c|}{$\begin{array}{l}\text { Extrusa } \\
\text { Extrusa }\end{array}$} & \multicolumn{2}{|c|}{$\begin{array}{l}\text { Suplementos } \\
\text { Supplements }\end{array}$} \\
\hline & $\begin{array}{c}\text { Período } 1 \\
\text { Period } 1\end{array}$ & $\begin{array}{c}\text { Período } 2 \\
\text { Period } 2\end{array}$ & $\begin{array}{c}\text { Período } 3 \\
\text { Period } 3\end{array}$ & $\begin{array}{l}\text { MS } \\
M S\end{array}$ & $\begin{array}{l}\text { TS } \\
T S\end{array}$ \\
\hline $\begin{array}{l}\mathrm{MS} \\
D M\end{array}$ & 113,5 & 137,6 & 128,1 & 817,6 & 795,5 \\
\hline MO & 893,2 & 909,0 & 899,8 & 966,3 & 936,8 \\
\hline $\begin{array}{l}\mathrm{PB} \\
C P\end{array}$ & 111,4 & 79,5 & 106,9 & 258,0 & 243,0 \\
\hline $\begin{array}{l}\mathrm{EE} \\
E E\end{array}$ & 16,4 & 10,7 & 12,0 & 3,7 & 1,4 \\
\hline $\begin{array}{l}\text { CHOT } \\
T C\end{array}$ & 765,4 & 818,8 & 780,9 & 698,6 & 692,4 \\
\hline $\begin{array}{l}\text { FDN } \\
N D F\end{array}$ & 714,1 & 737,2 & 700,3 & 119,7 & 443,1 \\
\hline $\begin{array}{l}\text { CNE } \\
N S C\end{array}$ & 51,3 & 81,6 & 80,6 & 578,9 & 249,3 \\
\hline $\begin{array}{l}\text { Cinzas } \\
\text { Ash }\end{array}$ & 106,8 & 91,0 & 100,2 & 39,7 & 63,2 \\
\hline
\end{tabular}


1344 Rev. bras. zootec.

Ao se relacionar o consumo ao peso vivo dos animais, utilizou-se como referência o peso médio do período.

Oexperimento base foi conduzido em delineamento em blocos casualizados, sendo os suplementos analisados como efeito principal e os períodos experimentais considerados como blocos. Para análise do comportamento do pH e concentração de amônia ruminal adotouse esquema de subdivisão de parcelas em função dos tempos de coleta. Para realização das comparações entre médias, adotou-se o teste de Newman Keulls, sendo todas as análises realizadas por intermédio do programa SAEG, versão 7.1, adotando-se $\alpha=0,05$.

\section{Resultados e Discussão}

Os valores de disponibilidade de matéria seca total, matéria seca de folhas verdes e matéria seca verde total são expressos na Tabela 3. Os valores para MS total encontram-se acima do limite de 2000 $\mathrm{kg} / \mathrm{ha}$ de MS, descrito por MINSON (1990), como mínimo para não restringir o consumo a pasto e superiores aos 4662 e $1108 \mathrm{~kg} / \mathrm{ha}$ de MS e MSV, respectivamente, citados por EUCLIDES et al. (1992), ao analisarem pastagem de Brachiaria decumbens, como não-limitantes à seleção. Infere-se, portanto, que a disponibilidade da massa forrageira possibilitou pastejo irrestrito e não ofereceu entraves à capacidade seletiva dos animais em todos os períodos experimentais, gerando, conseqüentemente, a possibilidade de maximização do consumo de matéria seca.

As médias para os consumos de MS, forragem, FDN e PB são expressas na Tabela 4. Não houve diferenças significativas $(\mathrm{P}>0,05)$ para quaisquer medidas de consumo.

Segundo afirmativas de LENG (1990), KARGES et al. (1992), POPPI e McLENNAN (1995) e HESS et al. (1996), esperar-se-iam aumentos no consumo total de MS por intermédio do maior consumo de energia, que tenderia a favorecer a retenção de nitrogênio pelo animal. Contudo, ELIZALDE et al. (1998) também não encontraram efeitos sobre o consumo total, quando forneceram suplementos à base de milho e, ou, glúten de milho a animais em pastagens durante a época das águas.

Animais em pastejo têm seu consumo influenciado pelos mesmos fatores que agem sobre animais em confinamento, sendo, contudo, acrescidos de outros fatores específicos a ambientes pastoris (MINSON, 1990). Dessa forma, fontes de variação naturalmente não submetidas ao controle experimental influem no comportamento de consumo, ampliando a dispersão dos dados coletados, dificultando a redução do intervalo de confiança em torno das estimativas e, conseqüentemente, a obtenção de diferenças estatisticamente significativas, o que corrobora os altos coeficientes de variação demonstrados na Tabela 4.

De acordo com os dados da Tabela 4, observa-se que os consumos total, de forrageme de FDN foram reduzidos, emmédia,em 21,2,33,6e 28,9\%, respectivamente, embora sem efeito significativo $(\mathrm{P}>0,05)$, pela suplementação, mostrando a presença de efeito substitutivo, corroborando os relatos de MINSON (1990), PORDOMINGO et al. (1991) e CATON e DHUYVETTER (1997). O efeito substitutivotendeu a ser mais acentuadopara os suplementos compostos por milho em grão.

HESS et al. (1996), ao fornecerem milho ou farelo de trigo a novilhos, durante os meses de verão, encontraram efeito substitutivo em todos os suplementos e concluíram que, ao fornecerem farelo de trigo e milho em quantidades iguais $(0,34 \% \mathrm{PV})$, foram observados menores valores de substituição no farelo de trigo, embora, quando ampliado o fornecimento de trigo, para se nivelar ao conteúdo energético do milho, o efeito tenha sido similar. Conforme CATON e DHUYVETTER (1997) fontes energéticas constituídas por fibras prontamente degradáveis, como o farelo de trigo, possuem menor potencial de substituição na suplementação.

Semelhantemente ao consumo total e de forragem, o consumo de FDN não foi alterado significativamente pela suplementação $(\mathrm{P}>0,05)$. O valor médio encontrado foi de $12,8 \mathrm{~g} / \mathrm{kg} \mathrm{PV}$, muito próximo à média de 12,0 g/kg PV, sugerida por MERTENS (1992) como ponto de máximo consumo.

Tabela 3 - Médias e coeficientes de variação (CV\%) para disponibilidade de matéria seca total (MST) $(\mathrm{kg} /$ ha), disponibilidade de matéria seca de folhas (MSF) e verde (MSV), em kg/ha para a pastagem

Table 3 - Means and coefficient of variation (CV\%) for dry matter availability (DMA) ( $\mathrm{kg} / \mathrm{ha})$, green leaf dry matter (GLDM) and green dry matter (GDM) in $\mathrm{kg} / \mathrm{ha}$ on pasture

\begin{tabular}{lccc}
\hline & \multicolumn{3}{c}{ Períodos experimentais } \\
& Experimental periods \\
\cline { 2 - 4 } & 1 & 2 & 3 \\
\hline MST(CV\%) & $7260(17,89 \%)$ & $11211(3,74 \%)$ & $10174(28,37 \%)$ \\
$D M A(C V \%)$ & & 2178 & 1278 \\
\hline MSF & 1746 & & 7791 \\
$G L D M$ & & 8724 & \\
MSV & 4344 & & \\
$G D M$ & & & \\
\hline
\end{tabular}




\section{DETMANN et al.}

As digestibilidades da MS, FDN e PB são mostradas na Tabela 5. Não foram encontradas diferenças $(\mathrm{P}>0,05)$ entre os valores apresentados.

DIAS et al. (2000), ao alimentarem novilhos F1 Limousin $\mathrm{x}$ Nelore em confinamento, com níveis crescentes de concentrado, encontraram digestibilidades médias da MS em torno de $58,8 \%$, com consumo médio de FDN de $0,62 \%$ PV, e concluíram ser o consumo limitado por fatores fisiológicos.

Nesse enfoque, observa-se que a digestibilidade média da MS obtida neste trabalho (Tabela 5) foi superior às obtidas por DIAS et al. (2000) e, apesar de o consumo de FDN ter sido superior ao observado por esses autores, observaram-se reduções numericamente discrepantes quanto ao consumo de FDN, quando se comparam os valores provenientes de animais suplementados ao controle, sem suplementação.
O desempenho de um animal em pastejo é função direta e proporcional à abundância de forragem que lhe é disponível. A relação entre consumo e abundância de forragem é denominada resposta funcional, sendo usualmente descrita por uma função curvilinear, onde a taxa de consumo aumenta com a altura ou biomassa da planta até se atingir uma assíntota decorrente da saturação em se processar o alimento (CARVALHO, 1997). A alta disponibilidade de massa forrageira encontrada (Tabela 3) possivelmente levou à saturação na resposta funcional do consumo, possibilitando alta seletividade, que levaria à alta digestibilidade da MS ingerida. Dessa forma, a adição de componentes de alto potencial de digestão à dieta pode ter rompido o limite de energia digestível limitante de consumo, invertendo o principal mecanismo regulatório, de físico para fisiológico, como descrito por MERTENS (1992), o que justificaria o menor consumo de FDN nos animais suplementados (Tabela 4).

Tabela 4 - Médias e coeficientes de variação (CV\%) para os consumos de matéria total (CMST), matéria seca de forragem (CMSF), proteína bruta (PB) e FDN (CFDN), em função dos diferentes tratamentos

Table 4 - Means and coefficients of variation (CV\%) of total dry matter (TDMI), forage (FI), crude protein (CPI) and neutral detergent fiber (NDFI) intakes, according to different treatments

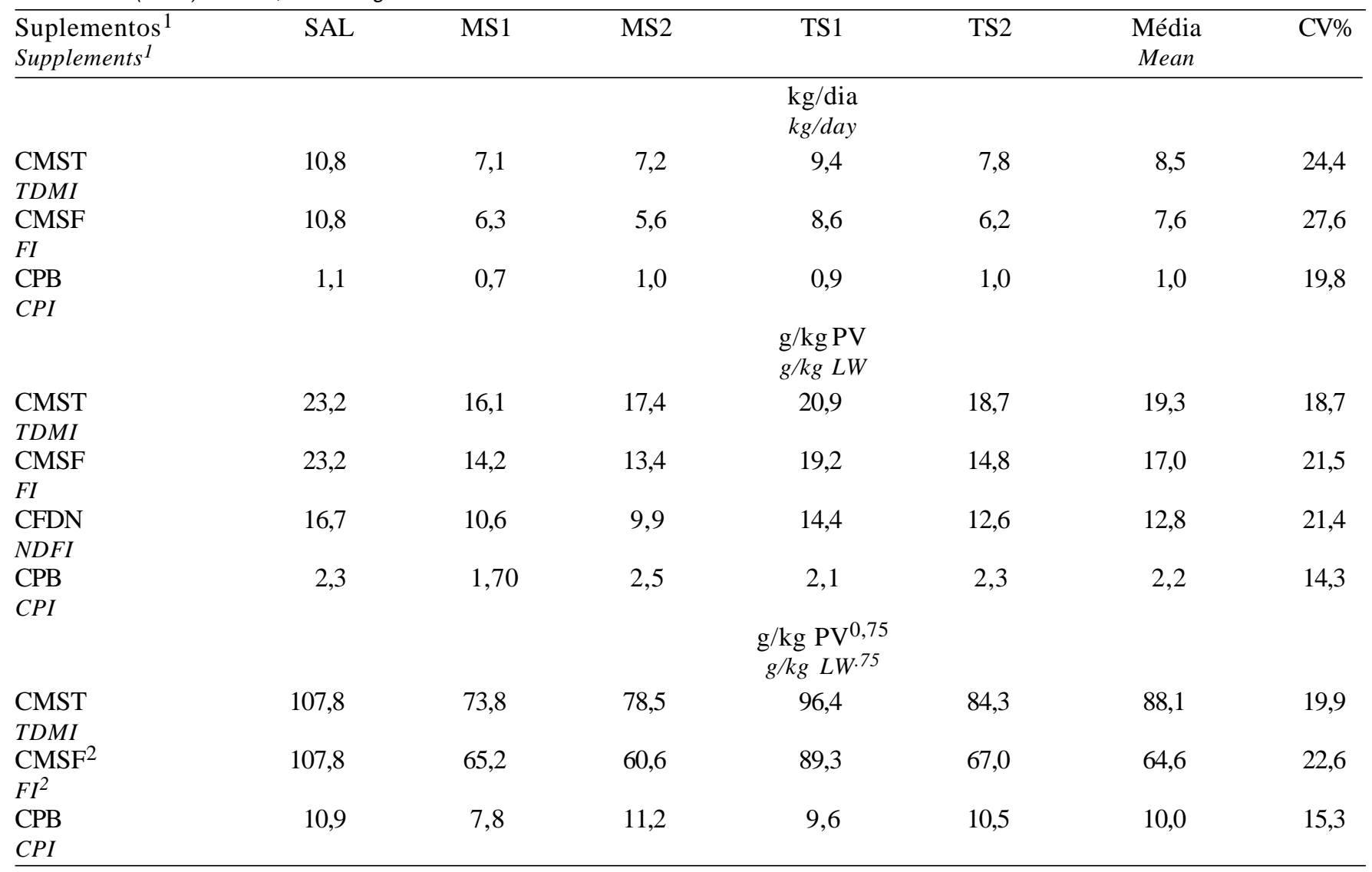

${ }_{1}$ As médias dispostas dentro de uma mesma linha não diferem pelo teste $F(P>0,05)$.

2 As médias para CMSF ( $\mathrm{g} / \mathrm{kg} P \mathrm{PV}^{0,75}$ ) não diferem pelo teste de Newman Keulls $(\mathrm{P}>0,05)$.

${ }^{1}$ Means, within a row, are not different $(P>.05)$ by $F$ test.

${ }^{2}$ Means for FI (g/kg LW $\left.W^{0.75}\right)$, within a row, are not different $(P>.05)$ by Newman Keulls test . 
1346 Rev. bras. zootec.

Tabela 5 - Médias e coeficientes de variação (CV\%) para a digestibilidade aparente da matéria seca (DMS), fibra em detergente neutro (DFDN) e proteína bruta (DPB), em porcentagem da matéria seca, para a dieta total, em função dos diferentes tratamentos

Table 5 - Means and coefficients of variation (\%CV) for apparent digestibility of dry matter (DMD), neutral detergent fiber (NDFD) and crude protein (CPI), in dry matter percentage, for the total diet, according to different treatments

\begin{tabular}{|c|c|c|c|c|c|c|c|}
\hline & \multicolumn{7}{|c|}{$\begin{array}{c}\text { Tratamentos } \\
\text { Treatments }\end{array}$} \\
\hline & SAL & MS1 & MS2 & TS1 & TS2 & Média & CV\% \\
\hline DMS & 69,7 & 68,0 & 59,5 & 66,3 & 63,3 & 65,4 & 14,0 \\
\hline $\begin{array}{l}D M D \\
\text { DFDN }\end{array}$ & 72,4 & 60,3 & 54,4 & 67,8 & 63,2 & 63,6 & 14,8 \\
\hline $\begin{array}{l}N D F D \\
\text { DPB } \\
C P D\end{array}$ & 68,6 & 63,3 & 63,0 & 65,0 & 67,2 & 65,4 & 10,9 \\
\hline
\end{tabular}

As médias dispostas dentro de uma mesma linha não diferem pelo teste $F(P>0,05)$.

Means, within a row, are not different $(P>05)$ by $F$ test.

O tratamento controle apresentou consumo de FDN superior à média proposta por MERTENS (1992) (Tabela 4). Contudo, em animais com alta demanda energética, como bovinos em crescimento, pode ocorrer ampliação da capacidade de enchimento, em função da necessidade de maior consumo (ALLEN, 1996), que torna o entrave físico numericamente relativo, e não absoluto, em função da exigência energética, justificando o consumo de FDN superior a $12 \mathrm{~g} / \mathrm{kg}$ PV.

A possibilidade de seleção de componentes da pastagem de alta digestibilidade, proporcionada pela elevada disponibilidade de massa forrageira (Tabela 3) parece ter influenciado, de forma semelhante, a utilização de nutrientes, possivelmente constituindo entrave ao aparecimento de efeito aditivo na digestibilidade pela inclusão de alimentos de alta digestão à dieta, via suplementação, comumente observado com volumosos de menor qualidade (McCOLLUN e GAYLEAN, 1985; KRYSL et al., 1989; e LINTZENICH et al., 1995).

Os valores de $\mathrm{pH}$ ruminal não sofreram influências de suplemento $(\mathrm{P}>0,05)$ e interação suplemento $X$ tempo $(\mathrm{P}>0,05)$, mas houve efeito significativo de tempo de coleta $(\mathrm{P}<0,01)$. A equação de regressão ajustada em função do tempo pós-suplementação e seu coeficiente de determinação são expressos na Figura 1.

Embora significativa, a amplitude de variação de pH em função do tempo foi reduzida, sendo o ponto de mínimo estimado em 6,3, ocorrendo 3,2 horas após o fornecimento do suplemento. Observa-se que os valores observados estão acima do limite de 6,2 proposto por HOOVER (1986) como inibitório à digestão da fibra, embora os níveis basais avaliados imediatamente antes ao fornecimento do suplemento não se encontrem próximos a 6,7 , em que haveria ótimo crescimento microbiano (VAN SOEST, 1994).

O perfil encontrado é condizente com os resultados de KRYSL et al. (1989), DelCURTO et al. (1991) e LINTZENICH et al. (1995). Segundo afirmação de CATON e DHUYVETTER (1997), as fontes energéticas fibrosas tendem a apresentar resultados similares aos grãos, como os encontrados neste trabalho. Os autores afirmaram que a queda de $\mathrm{pH}$ está mais vinculada ao nível de suplementação do que propriamente à fonte. Assim, infere-se que, em condições semelhantes às estudadas, a adição de $2 \mathrm{~kg}$ de suplemento não é capaz de alterar o pH ruminal em níveis danosos à digestão ruminal da fibra.

Resultados semelhantes foram relatados por HESS et al. (1996), que, ao suplementarem novilhos com milho ou farelo de trigo, não encontraram diferenças significativas entre os suplementos testados e o grupo controle, sem suplementação, quanto ao $\mathrm{pH}$ ruminal, porém, os animais suplementados apresentaram menor taxa de degradação in situ da FDN, que possivelmente refletiria em menor digestão total da fibra.

A análise de concentração ruminal de $\mathrm{N}$-amoniacal demonstrou efeitos significativos para suplemento $(\mathrm{P}<0,01)$, tempo de coleta $(\mathrm{P}<0,01)$ e interação suplemento e tempo $(\mathrm{P}<0,01)$. Portanto, procedeu-se a análises das médias de concentração de cada suplemento dentro de cada tempo de coleta (Tabela 6) e à estimação das equações de regressão da concentração para cada suplemento, em função do tempo, expressas na Figura 2.

As análises dos dados monstrou o mesmo nível basal de $\mathrm{N}$-amoniacal entre tratamentos $(\mathrm{P}>0,05)$ $($ Tempo $=0)$, apresentando valor médio de $8,5 \mathrm{mg} \mathrm{N}$ $\mathrm{NH}_{3} / \mathrm{dL}$ de líquido ruminal, estando acima dos $5 \mathrm{mg} / \mathrm{dL}$ sugeridos pelo NRC (1988), para maximização da 


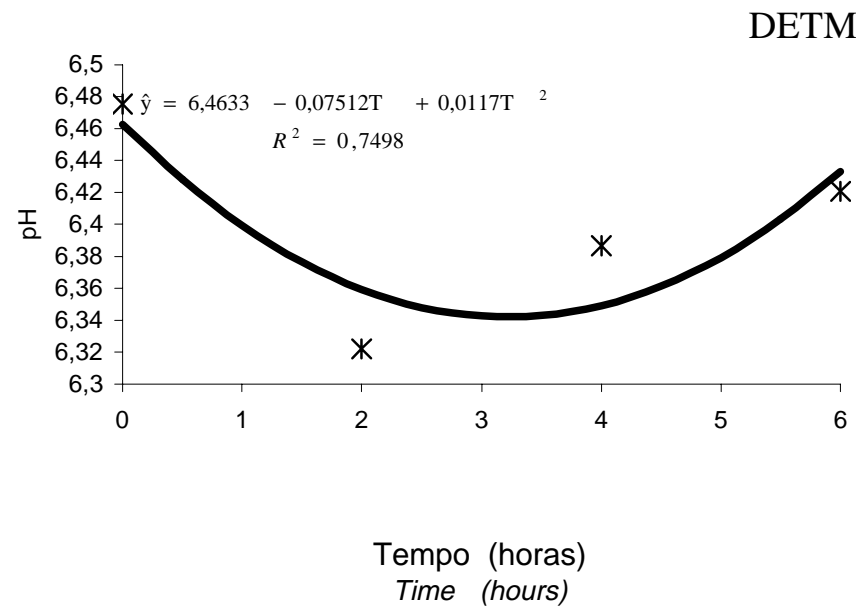

Figura 1 - Estimativas do pH ruminal, em função dos tempos (T) de coleta.

Figure 1 - Estimates of ruminal $\mathrm{pH}$ in function of collection times $(T)$.

digestão ruminal da matéria seca, embora inferior ao mínimo de $10 \mathrm{mg} / \mathrm{dL}$ sugerido por LENG (1990), para a mesma finalidade, em condições tropicais.

Efeito interativo semelhante foi encontrado por HESS et al. (1996), no entanto, seus resultados mostraram elevação dos níveis basais de $\mathrm{N}$-amoniacal para os animais suplementados, contrário do obtido neste trabalho.

Nos demais tempos analisados, os níveis de $\mathrm{N}$ amoniacal foram mais elevados para o suplemento TS2 $(\mathrm{P}<0,05)$, chegando a alcançar níveis superiores a $20 \mathrm{mg} / \mathrm{dL}$, valor sugerido por LENG (1990) como ponto de maximização do consumo de MS, em condições tropicais. Para os tempos 2, 4 e 6 horas, os suplementos TS1 e MS2 não diferiram entre si ( $\mathrm{P}>0,05)$, mesmo suprindo níveis diferentes de proteína, o que pode ser resultante de maior taxa de degradação da proteína do farelo de trigo, conforme verificado por VALADARES FILHO et al. (1990). Para todos os tempos, o suplemento MS1 não diferiu do controle. Esta similaridade pode ser melhor observada pelos gráficos e pelas equações apresentadas na Figura 2, na qual não foram encontrados efeitos de tempo quanto à concentração de $\mathrm{N}$-amoniacal para ambos os tratamentos $(\mathrm{P}>0,05)$.

Os tratamentos MS2, TS1 e TS2 apresentaram perfis quadráticos para a concentração de $\mathrm{N}$-amoniacal (Figura 2). Os tratamentos à base de farelo de trigo e farelo de soja (TS1 e TS2) apresentaram pontos de máxima concentração (2,8 e 3,5 horas) anteriores ao MS2 (4,1 horas), corroborando a hipótese de maior degradabilidade protéica do farelo de trigo.
1347

Tabela 6 - Médias dos valores de concentração de $\mathrm{N}-\mathrm{NH}_{3}$ $(\mathrm{mg} / \mathrm{dL})$ no líquido ruminal para os diferentes tempos (horas), após o fornecimento do suplemento, em função dos diferentes tratamentos

Table 6 - Mean concentration of $\mathrm{N}^{-\mathrm{NH}_{3}}(\mathrm{mg} / \mathrm{dL})$ in ruminal liquid for different times (hours) after supplementation, according to different treatments

\begin{tabular}{lrrrc}
\hline & \multicolumn{4}{c}{ Tempo } \\
& \multicolumn{5}{c}{ Time } \\
\cline { 2 - 5 } $\begin{array}{l}\text { Suplemento } \\
\text { Supplement }\end{array}$ & 0 & 2 & 4 & 6 \\
\hline SAL & $7,4^{\mathrm{A}}$ & $7,1^{\mathrm{C}}$ & $6,6^{\mathrm{C}}$ & $7,8^{\mathrm{B}}$ \\
MS1 & $8,2^{\mathrm{A}}$ & $8,2^{\mathrm{C}}$ & $9,2^{\mathrm{C}}$ & $9,4^{\mathrm{AB}}$ \\
MS2 & $8,2^{\mathrm{A}}$ & $14,4^{\mathrm{B}}$ & $15,5^{\mathrm{B}}$ & $14,4^{\mathrm{A}}$ \\
TS1 & $10,8^{\mathrm{A}}$ & $14,8^{\mathrm{B}}$ & $11,3^{\mathrm{BC}}$ & $11,3^{\mathrm{AB}}$ \\
TS2 & $7,7^{\mathrm{A}}$ & $20,1^{\mathrm{A}}$ & $22,2^{\mathrm{A}}$ & $14,9^{\mathrm{A}}$ \\
\hline
\end{tabular}

Médias, na coluna, seguidas por letras diferentes, são diferentes $(P>0,05)$ pelo teste Newman Keulls.

Means, within a column, followed by different letters are different $(P>05)$ by Newman Keulls test.

O aumento da concentração amoniacal, em função do tempo, é concordante com os resultados expostos por HESS et al. (1996), porém contrário a PORDOMINGO et al. (1991), que encontraram resultados relativamente constantes, no decorrer do tempo, ao suplementarem novilhos com níveis crescentes de milho em grão, diferenças provavelmente atribuídas à não-utilização de fonte protéica adicional, como empregado neste estudo.

Os resultados contrariam as afirmações de KARGES et al. (1992) e POPPI e McLENNAN (1995), os quais relatam que haveria reduções no nível amoniacal, em virtude de possível aumento na disponibilidade energética para síntese microbiana, embora, o uso do farelo de soja possa ter mascarado este efeito. No entanto, fazem-se necessários estudos de eficiência microbiana para o melhor entendimento do mecanismo envolvendo o fornecimento energético extra sob estas condições.

Não havendo diferenças significativas no comportamento de $\mathrm{pH}$ ruminal, não se faz válida, sob estas condições, a afirmativa de LANA et al. (1998) sobre menores concentrações de $\mathrm{N}$-amoniacal, em virtude de maiores quedas no $\mathrm{pH}$, ocasionadas por menor atividade proteolítica no rúmen. O comportamento encontrado parece condizer com a afirmativa de OBARA et al. (1991), em que maiores concentrações de amônia podem ser atribuídas à contribuição de N, a partir do suplemento.

Os valores obtidos para taxa de passagem não diferiram entre tratamentos $(\mathrm{P}>0,05)$ (Tabela 7), 
1348 Rev. bras. zootec.

Tabela 7 - Médias e coeficientes de variação (CV\%) para taxa de passagem ruminal (TPR) e tempo médio de retenção total de digesta (TMRT), em horas, em função dos diferentes tratamentos

Table 7 - Means and coefficients of variation (CV\%) for ruminal rate of passage (RRP) and total mean retention time of digesta (TMRT), in hours, according to different treatments

\begin{tabular}{|c|c|c|c|c|c|c|c|}
\hline \multirow[b]{2}{*}{ Itens } & \multicolumn{7}{|c|}{$\begin{array}{c}\text { Tratamentos } \\
\text { Treatments }\end{array}$} \\
\hline & SAL & MS1 & MS2 & TS1 & TS2 & $\begin{array}{l}\text { Média } \\
\text { Means }\end{array}$ & $\mathrm{CV} \%$ \\
\hline TPR & 0,049 & 0,051 & 0,056 & 0,052 & 0,056 & 0,053 & 13,6 \\
\hline $\begin{array}{l}R R P \\
\text { TMRT } \\
M T R T\end{array}$ & 50,8 & 50,0 & 44,9 & 48,9 & 45,8 & 48,1 & 12,0 \\
\hline
\end{tabular}

As médias dispostas dentro de uma mesma linha não diferem pelo teste $F(P>0,05)$.

Means, within a row, are not different $(P>.05)$ by $F$ test.

$$
\begin{array}{ll}
\hat{\mathrm{y}}_{\mathrm{SAL}}=\overline{\mathrm{y}}=7,4983 & \\
\hat{\mathrm{y}}_{\mathrm{MS} 1}=\overline{\mathrm{y}}=8,0721 & \\
\hat{\mathrm{y}}_{\mathrm{MS} 2}=8,3302+3,7486 \mathrm{~T}-0,4593 \mathrm{~T}^{2} & \mathrm{R}^{2}=0,9868 \\
\hat{\mathrm{y}}_{\mathrm{TS} 1}=11,3151+1,4266 \mathrm{~T}-0,2536 \mathrm{~T}^{2} & \mathrm{R}^{2}=0,4287 \\
\hat{\mathrm{y}}_{\mathrm{TS} 2}=7,7357+8,5981 \mathrm{~T}-1,2387 \mathrm{~T}^{2} & \mathrm{R}^{2}=0,9980
\end{array}
$$

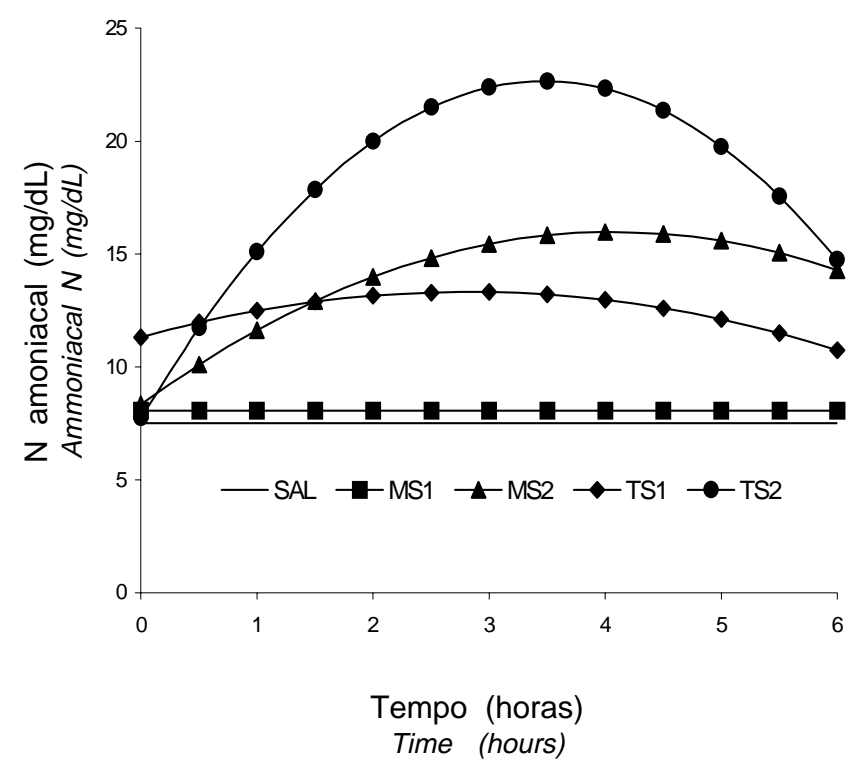

Figura 2 - Estimativas da concentração de $\mathrm{N}-\mathrm{NH}_{3}(\mathrm{mg} / \mathrm{dL})$ do líquido ruminal, em função dos tempos ( $\mathrm{T}$ ) de coleta, para cada tratamento.

Figure 2 - Estimates of $\mathrm{N}-\mathrm{NH}_{3}$ concentration $(\mathrm{mg} / \mathrm{dL})$ in ruminal liquid, in function of collection times (T), according to different treatments. apresentando valor médio de 0,053 , próximos a 0,05 , valor sugerido pelo AGRICULTURAL AND FOOD RESEARCH COUNCIL - AFRC (1993) para categorias semelhantes. A invariabilidade observada é concordante com JUDKINS et al. (1987), os quais afirmaram que, sob dietas selecionadas com teores protéicos superiores a $8 \%$, como observado neste trabalho (Tabela 2), a suplementação não influi na taxa de passagem ruminal.

HESS et al. (1996), apesar de não terem encontrado efeitos sobre a taxa de passagem da fase particulada da digesta ruminal, afirmaram que a suplementação reduziu o tempo médio de retenção total, efeito não-observado neste trabalho $(\mathrm{P}>0,05)$.

\section{Conclusões}

Sob condições de alta possibilidade de seleção da pastagem pelo animal, o uso de suplementos reduziu o consumo total de matéria seca e forragem em 21,2 e $33,6 \%$, respectivamente, embora sem efeitos significativos, e levou à inibição do aparecimento de efeitos aditivos sobre a digestão total da matéria seca e das frações fibrosa e protéica da dieta.

A suplementação durante o período das águas em pastagens tropicais, em níveis de até $2 \mathrm{~kg} / \mathrm{dia}$, não foi capaz de causar alterações danosas à digestão fibrosa no $\mathrm{pH}$ ruminal. A concentração amoniacal, por sua vez, foi alterada em função do nível e, possivelmente, da degradabilidade da proteína suplementar, embora concentrações basais satisfatórias sejam encontradas sob estas condições. 


\section{Referências Bibliográficas}

AGRICULTURAL AND FOOD RESEARCH COUNCIL - AFRC. 1993. Energy and protein requirements of ruminants. Cambridge: CAB International. 159p.

ALLEN, M.S. 1996 Physical constraints on voluntary intake of forages by ruminants. J. Anim. Sci., 74(12):3063-3075.

CARVALHO, P.C.F. 1997. A estrutura da pastagem e o comportamento ingestivo de ruminantes em pastejo. In: JOBIM, C.C., SANTOS, G.T., CECATO, U. (Eds.) Simpósio sobre avaliação de pastagens com animais. Maringá: Cooper Graf. Artes Gráficas Ltda. p.25-52.

CATON, J.S., DHUYVETTER, D.V. 1997. Influence of energy supplementation on grazing ruminants: requirements and responses. J. Anim. Sci., 75(2):533-542.

CHASE JR., C.C., HIBBERD, C.A. 1987. Utilization of low-quality native grass hay by beef cow feed increased quantities of corn grain. J. Anim. Sci., 65(2):557-566.

DelCURTO, T., COCHRAN, R.C., CORAH, L.R. et al. 1990 Supplementation of dormant Tallgrass-Prarie forage: II. Performance and forage utilization characteristics in grazing beef cattle receiving supplements of different protein concentrations. J. Anim. Sci., 68(2):532-542.

DIAS, H.L.C., VALADARES FILHO, S.C., COELHO DA SILVA, J.F.C. et al. 2000. Consumo e digestões totais e parciais em novilhos F1 Limuisin X Nelore alimentados com dietas contendo cinco níveis de concentrado. R. Bras. Zootec., 29(2):545-554.

ELIZALDE, J.C., CREMIN, J.D., FAULKNER, D.B. et al. 1998. Performanceand digestion by steers grazing tall fescue and supplement with energy and protein. J. Anim. Sci., 76(4):1691-1701.

EUCLIDES, V.P.B., MACEDO, M.C.M., OLIVEIRA, M.P. 1992. Avaliação de diferentes métodos de amostragem (para se estimar o valor nutritivo de forragens) sob pastejo. R. Soc. Bras. Zootec., 21(2):691-702

FAHEY JR., G.C., BERGER, L.L. 1988. Carbohydrate nutrition of ruminants. In: CHURCH, D.C. (Ed.) The ruminant animal: digestive physiology and nutrition. New Jersey: Prentice Hall. p.269-297.

GROVUM, W.L., WILLIANS, V.J. 1973. Rate of passage of digesta in sheep. 4. Passage of marker through the alimentary tract and the biological relevance of rate-constants derived from the changes in concentration of markers in faeces. Br. J. Nutr., 30(2):313-329.

HAFLEY, J.L., ANDERSON, B.E., KLOPFENSTEIN, T.J. 1993. Supplementation of growing cattle grazing warm-season grass with proteins of various ruminal degradabilities. J. Anim. Sci., 71(2):522-529.

HANNAH, S.M., COCHRAN, R.C., VANZANT. E.S. et al. 1991. Influence of protein supplementation on site and extent of digestion, forage intake, and nutrient flow characteristics in steers consuming dormant Bluestem-Range forage. J. Anim. Sci., 69(6):2624-2633

HESS, B.W., KRYSL,L.J.,JUDKINS, M.B. etal. 1996. Supplemental corn or wheat bran for steers grazing endophyte-free fescue pasture: effects on live weight gain, nutrient quality, forage intake, particulate and fluid kinetic, ruminal fermentation, and digestion. J. Anim. Sci., 74(5):1116-1125.

HOOVER, W.H. 1986. Chemical factors involved in ruminal fiber digestion. J. Dairy Sci., 68(1):40-44.

HOPPER, J.T., HOLLOWAY, J.W., BUTTS JR., W.T. 1978 Animal variation in chromiun sesquioxide excretion patterns of grazing cows. J. Anim. Sci., 46(4):1098-1102.

JUDKINS, M.B., WALLACE, J.D., GALYEAN, M.L. et al. 1987. Passage rates, rumen fermentation and weight change in protein supplemented grazing cattle. J. Range Manage., 40(2):100-104.

KARGES, K.K., KLOPFENSTEIN, T.J., WILKERSON, V.A. et al. 1992. Effects of ruminal degradable protein and escape protein supplements on steers grazing summer native range. J. Anim. Sci., 70(6):1957-1964

KENNEDY, P.M., MURPHY, M.R. 1988. The nutritional implications of differential passage of particles through the ruminant alimentary tract. Nut. Res. Rev., 1(1):189-208.

KRYSL, L.J., BRANINE, M.E., CHEEMA, A.U. et al. 1989.

Influence of soybean meal and sorghum grain supplementation on intake, digesta kinetics, ruminal fermentation, site and extent of digestion and microbial protein synthesis in beef steers grazing blue grama rangeland. J. Anim. Sci., 67(11):3040-3051.

LANA, R.P., RUSSELL, J.B., VAN AMBURGH, M.E. 1998. The role of $\mathrm{pH}$ in regulating ruminal methane and ammonia production J. Anim. Sci., 76(8):2190-2196.

LENG, R.A. 1990. Factors affecting the utilization of "poor-quality" forages by ruminants particularly under tropical conditions. Nut Res. Rev., 3(3):277-303.

LINTZENICH, B.A., VANZANT, E.S., COCHRAN, R.C. et al 1995. Influence of processing supplemental alfafa on intake and digestion of dormant Bluestem-Range forage by steers. J. Anim. Sci. 73(4):1187-1195.

LIPPKE, H., ELLIS, W.C., JACOBS, B.F. 1986. Recovery of indigestible fiber from feces of sheep and cattle on forage diets. J. Dairy Sci., 69(2):403-412.

McCOLLUM,F.T., GALYEAN, M.L. 1985. Influence of cottonseed meal supplementation in voluntary intake, rumen fermentation and rate of passage of prarie hay in beef steers. J. Anim. Sci., 60(2):570-577.

MERTENS, D.R. Analysis of fiber in feeds and its use in feed evaluation and ration formulation. In: SIMPÓSIO INTERNACIONAL DE RUMINANTES, 1997, Lavras. Anais... Lavras: SBZ, 1992. p.1-33.

MINSON, D.J. 1990. Forage in ruminant nutrition. San Diego: Academic Press. 483p.

NATIONAL RESEARCH COUNCIL - NRC. 1996. Nutrient requirements of beef cattle. 7.ed. Washington, D.C.: Academic Press. 242p.

NATIONAL RESEARCH COUNCIL - NRC. 1988. Nutrient requirements of dairy cattle. 6.ed. Washington, D.C.: Academic Press.158p.

OBARA, Y., DELLOW, D.W., NOLAN, J.V. 1991. The influence of energy-rich supplements on nitrogen kinetics in ruminants. In: TSUDA, T., SASAKI, Y., KAWASHIMA, R. (Eds.) Physiological aspects of digestion and metabolism in ruminants. New York: Academic Press. p.515-539.

PAULINO, M.F., BORGES, L.E., CARVALHO, P.P. et al. Fontes de proteína em suplementos múltiplos sobre o desenvolvimento de novilhos e novilhas mestiços em pastoreio durante a época das águas. In: REUNIÃO ANUAL DA SOCIEDADE BRASILEIRA DE ZOOTECNIA, 33, 1996, Fortaleza. Anais... Fortaleza: SBZ, 1996. v.1, p.12-13.

POPPI, D.P., McLENNAN, S.R. 1995. Protein and energy utilization by ruminants at pasture. J. Anim. Sci., 73(1):278-290.

PORDOMINGO, A.J., WALLACE, J.D., FREEMAN, A.S. et al. 1991. Supplemental corn grain grazing native rangeland during summer. J. Anim. Sci., 69(4):1678-1687.

SILVA, D.J. 1990. Análise de alimentos (métodos químicos e biológicos). 2.ed. Vicosa: Imprensa Universitária. 156p.

SNIFFEN, C.J., O'CONNOR, J.D., VAN SOEST, P.J. et al. 1992. A net carbohydrate and protein system for evaluating cattle diets: II. Carbohydrate and protein availability. J. Anim. Sci., 70(10):3562-3577.

UDÉN, P., COLUCCI, P.E, VAN SOEST, P.J. 1980. Investigation of chromium, cerium and cobalt as markers in digesta. Rate of passage studies. J. Sci. Food Agric., 31(7):625-632.

VALADARES FILHO, S.C., COELHO DA SILVA, J.F., LEÃO, M.I. et al. 1990. Degradabilidade in situ da matéria seca e proteína bruta de vários alimentos em vacas em lactação. R. Soc. Bras. Zootec., 19(6):512-521.

VAN SOEST, P.J. 1994. Nutritional ecology of the ruminant. 2.ed. Ithaca: Cornell University Press. 476p.

WALDO, D.R. 1986. Effect of forage quality on intake and forageconcentrate interactions. J. Dairy Sci., 69(2):617-631.

WILLIANS, C.H., DAVID, D.J., IISMA, O. 1962. The determination of chromic oxide in faeces samples by atomic absorption spectrophotometry. J. Agric. Sci., 59(3):381-385.

Recebido em: 08/02/00

Aceito em: 08/05/01 